\title{
MODSNOW-Tool: an operational tool for daily snow cover monitoring using MODIS data
}

\author{
Abror Gafurov (1), Stefan Lüdtke (1), Katy Unger-Shayesteh (1), Sergiy Vorogushyn (1), Tilo Schöne (2), \\ Sebastian Schmidt (1), Olga Kalashnikova (3), and Bruno Merz (1) \\ (1) GFZ German Research Centre for Geosciences, Section 5.4: Hydrology, Potsdam, Germany (gafurov@ gfz-potsdam.de), \\ (2) GFZ German Research Centre for Geosciences, Section 1.2: Global Geomonitoring and Gravity Field, Potsdam, Germany, \\ (3) Central Asian Institute for Applied Geosciences (CAIAG), Bishkek, Kyrgyzstan
}

Spatially distributed snow cover information in mountain areas is extremely important for water storage estimations, seasonal water availability forecasting, or the assessment of snow-related hazards (e.g. enhanced snow-melt following intensive rains, or avalanche events). Moreover, spatially distributed snow cover information can be used to calibrate and/or validate hydrological models.

We present the MODSNOW-Tool - an operational monitoring tool offers a user-friendly application which can be used for catchment-based operational snow cover monitoring. The application automatically downloads and processes freely available daily Moderate Resolution Imaging Spectroradiometer (MODIS) snow cover data.

The MODSNOW-Tool uses a step-wise approach for cloud removal and delivers cloud-free snow cover maps for the selected river basins including basin specific snow cover extent statistics.

The accuracy of cloud-eliminated MODSNOW snow cover maps was validated for 84 almost cloud-free days in the Karadarya river basin in Central Asia, and an average accuracy of $94 \%$ was achieved. The MODSNOW-Tool can be used in operational and non-operational mode. In the operational mode, the tool is set up as a scheduled task on a local computer allowing automatic execution without user interaction and delivers snow cover maps on a daily basis. In the non-operational mode, the tool can be used to process historical time series of snow cover maps.

The MODSNOW-Tool is currently implemented and in use at the national hydrometeorological services of four Central Asian states - Kazakhstan, Kyrgyzstan, Uzbekistan and Turkmenistan and used for seasonal water availability forecast. 